\title{
Quality of Life of Preterm Children: Risk and Protective Factors ${ }^{1}$
}

\author{
Juliana Aparecida Martini ${ }^{2}$ \\ Universidade Estadual Paulista \\ "Júlio de Mesquita Filho" \\ Botucatu-SP, Brazil
}

\author{
Flávia Helena Pereira Padovani \\ Universidade Estadual Paulista \\ "Júlio de Mesquita Filho" \\ Botucatu-SP, Brazil
}

\author{
Gimol Benzaquen Perosa \\ Universidade Estadual Paulista \\ "Júlio de Mesquita Filho" \\ Botucatu-SP, Brazil
}

\begin{abstract}
Given the significant increase in survival rates of prematurely born children, this study assessed their quality of life at school age and identified potential risk and protective factors. We included 57 children with premature birth aged 5 to 8 years. Participants completed a cognitive test, and their parents assessed their behavior and quality of life. Most children presented an average or high intellectual level. Despite the mildly compromised quality of life, we observed a high prevalence of behavioral problems in older children. Male participants and behavioral problems were identified as risk factors for lower quality of life; this finding indicates the need to implement systematic monitoring services to facilitate adaptation of premature born children when entering in the school.
\end{abstract}

Keywords: quality of life, premature birth, risk factors, childhood development

\section{Qualidade de Vida em Crianças Nascidas Prematuras: Fatores de Risco e Proteção}

\begin{abstract}
Resumo: Considerando-se o aumento significativo nos índices de sobrevida de crianças nascidas prematuras, objetivou-se avaliar sua qualidade de vida em idade escolar e identificar possíveis fatores de risco e proteção. 57 crianças de 5 a 8 anos, nascidas prematuras, responderam a um teste cognitivo e os pais avaliaram seu comportamento e qualidade de vida. A maioria das crianças apresentou nível intelectual médio ou superior. Apesar do leve prejuízo na qualidade de vida, observou-se alta prevalência de problemas de comportamento nas crianças maiores. Identificou-se sexo masculino e problemas comportamentais como fatores de risco para qualidade de vida, sinalizando para a necessidade de serviços de acompanhamento antes do ingresso da criança nascida prematura na escola, visando facilitar sua adaptação.
\end{abstract}

Palavras-chave: qualidade de vida, nascimento prematuro, fatores de risco, desenvolvimento infantil

\section{Calidad de Vida en Niños Prematuros: Factores de Riesgo y Protección}

\begin{abstract}
Resumen: Ante el aumento significativo en las tasas de supervivencia de los recién nacidos prematuros, este estudio tuvo el objetivo de evaluar la calidad de vida de estos niños en edad escolar e identificar posibles factores de riesgo y protección. Cincuenta y siete niños de 5-8 años de edad, nacidos prematuros, contestaron una prueba cognitiva y los padres calificaron su comportamiento y calidad de vida. La mayoría de los niños presentó nivel intelectual promedio o superior. A pesar de pocos daños en la calidad de vida, fue encontrada alta prevalencia de problemas de conducta en los niños mayores. El sexo masculino y problemas conductuales se presentaron como factores de riesgo para la calidad de vida, lo que indica que son necesarios servicios de seguimiento para los niños nascidos prematuros antes que empiecen la escuela, para facilitar su adaptación.
\end{abstract}

Palabras clave: calidad de vida, nacimiento prematuro, factores de riesgo, desarrollo infantil

In the past several years, advances in healthcare have improved the survival of children born at a younger gestational age (23 or 24 weeks). According to World Health Organization (WHO) data, each year 15 million of children are born prematurely, and this incidence is expected to increase in the upcoming years (March of Dimes, Partnership for Maternal, Newborn \& Child Health, Save the Children, \& World Health Organization, 2012). Matijasevich et al. (2013)

\footnotetext{
${ }^{1}$ Article derived from the master's thesis of the first author under the supervision of Gimol Benzaquen Perosa, defended in 2012 in the Graduate Program of Collective Health of the Faculdade de Medicina de BotucatuUNESP. Acknowledgment: Health Utilities Inc (HUInc).

Support: National Council for Scientific and Technological Development (CNPq, Grant \# 474105/2010-5).

${ }^{2}$ Correspondence address:

Juliana Aparecida Martini. Rua Orlando Gamito, 171, apto 106, bloco 2. Bairro Cidade Jardim. CEP 18601-250. Botucatu-SP, Brazil. E-mail: julianaaparecidamartini@hotmail.com
}

reported premature birth rates of $11.8 \%$ in Brazil and $12.7 \%$ in the state of São Paulo in 2011.

Although most children survive, many of them develop disorders, incapacities and health complications, especially those born at a younger gestational age (March of Dimes et al., 2012; Quesada, Tristão, Pratesi, \& Wolf, 2014). In this sense, there is a growing need to obtain more information on their development and quality of life, with the aim to support prevention actions, health promotion, and follow-up programs.

Most studies of prematurity have prioritized assessment of neuropsychomotor and cognitive development, and few have focused on the quality of life of these children (Vieira \& Linhares, 2011). The scarcity of studies might be attributed to difficulty precisely defining quality of life and, consequently, methods for assessment. In the healthcare area, there are two predominant tendencies concerning this concept. Of these, the most generic one is adopted by WHO, which defines quality of life as "individuals' perception of their position in 
life in the context of the culture and value systems in which they live and in relation to their goals, expectations, standards and concerns" (The WHOQOL Group, 1995, p. 59). The other tendency aims to evaluate qualify of life for those with specific clinical features or after introduction of medications and other types of intervention (Soares et al., 2011).

This more specific second perspective evaluates the value that the individual assigns to life, considering functional deteriorations, perceptions and social conditions induced by disease and treatments, as well as by political and economic organization of care system (Horsman, Furlong, Feeny, \& Torrance, 2003; Soares et al., 2011). Assessments are based on useful theory and involve multiple domains and measurement of aspects of physical health, physiologic status, social relationships and level of independence of an individual facing specific situations; these assessments consider the importance of function for good adaptation of the individual in his or her environment (Horsman et al., 2003).

The number of studies of quality of life in children and adolescents is still low, both internationally and nationally. Studies of prematurely born children of preschool and school age are even more scarce (Soares et al., 2011; Vieira \& Linhares, 2011). One of the first studies in the 1990s found that prematurely born children had worse quality of life than full-term groups; however, their quality of life was also better than had been previously believed. Also, according to these authors, children included in the study were born approximately a decade before the evaluation, and the expectation is better performance in current survivors of neonatal intensive care units when evaluated at school age (Saigal et al., 1994).

Retrospectively studies carried out confirmed limitations in quality of life of preschool children born prematurely. A systematic review identified that premature children in preschool and school had worse quality of life indexes than full-term infants (Vieira \& Linhares, 2011). However, in adolescents and adults, the effects of prematurity and low birth weight on quality of life decreased with age, and the difference between full-term and premature birth was not maintained; this finding suggests that an adaptation process occurs over time (Hallin \& Stjernqvist, 2011).

In addition to prematurity and low birth weight, other variables associated with quality of life of prematurely born children can increase or ameliorate the risk. Stahlmann, Rapp, Herting e Thyen (2009), for example, reported that an intelligence quotient (IQ) lower than 70 was a predictor of poor quality of life in extremely premature children when they were 7 to 9 years old. Emotional and behavioral problems at 10 years of age were also a predictor of poor quality of life in extremely premature children at age 18 years (Verdehus et al., 2015).

Because current medical interventions are more focused on increasing life expectancy, despite a growing interest in improving quality of life of children and adolescents, new investigations are needed. Our study sought to evaluate qualify of life of extremely low birth weight children and associations with sociodemographic factors, birth conditions, and cognitive and behavioral performance, as well as to identify possible risk and protective factors.

\section{Method}

This prospective, cross-sectional study sought to evaluate patients in a multidisciplinary outpatient unit to assist premature children, born between 2002 and 2005, with gestational age younger than 37 weeks and birth weight lower than $1,500 \mathrm{~g}$, aged between 5 and 8 years at the time of data collection. The age range evaluated currently corresponds to initial period of formal education in Brazil.

\section{Participants}

Of 197 children eligible for participation in the study, many could not be found, declined to participate or could not participate because of difficulty obtaining transportation to access the outpatient unit. The final convenience sample was composed of 57 children.

Distribution of children by age range and sex was homogenous: $50.9 \%$ were age 5 to 6 years and were considered preschool age, and $48.1 \%$ were age 7 to 8 years; $57.9 \%$ were boys; and all children were formerly enrolled at school. Mean birth weight was $1,130 \mathrm{~g}$, and gestational age was 29 weeks. Children remained hospitalized after birth for about 52 days. Small for gestational age (SGA) was diagnosed in 31.5\% of children; however, $84.6 \%$ had an Apgar score greater than or equal to 7 at 5 minutes, indicating good recovery. During the first year of life, $28.1 \%$ of children needed to be re-admitted after discharge one or more times, and $49.0 \%$ were considered to have neuropsychomotor development delay (NPMD) by the medical team at the last medical consultation.

Mean maternal age at birth was 25 years (range, 16 to 44 years). Most mothers (78.6\%) reported having a partner, $51.2 \%$ had more than 8 years of education, and only $30.0 \%$ worked outside the home.

\section{Instruments}

To assess intelligence, we used the Wechsler Intelligence Scale for Children (WISC-III), translated and adapted to Brazilian Portuguese by Poppovic in 1964 (Wechsler, 2002). The test, composed of 13 subtests organized into two groups, verbal and execution, evaluates children aged 6 to 15 years. After calculation of pondering points, results were transformed into IQ, verbal intelligence quotient (VIQ) and execution intelligence quotient (EIQ). The reliability coefficient for a Brazilian sample was .92 for VIQ, .81 for EIQ and .93 for total IQ (Wechsler, 2002). For younger children, we used the Wechsler Preschool and Primary Scale of Intelligence (WPPSI), adapted to children aged 3 years, 6 months to 7 years. Because there is no translation or validation to Brazilian Portuguese, we used a version from Argentina coordinated by Jaime Bernstein, translated by Dália Ares. Reliability coefficients presented for the Argentina sample were .94 for VIQ, .93 for EIQ and .96 for total IQ (Wechsler, 1967/2006).

To assess behavioral problems, we used the Child Behavior Checklist (CBCL), completed by parents or a responsible person. There are two versions of the scale, depending on age range of children. The first is geared for children age 1.5 to 5 years and is composed of 100 items; the 
second, for children aged 6 to 18 years, consists of 113 items. With both versions, the person completing the instrument must record the frequency with which the child presents types of behavior or thinking: 0 , if the affirmation is not true, 1 if the affirmation is less true, and 2 if the affirmation is true. The result was transformed into a $\mathrm{T}$ score. The scale enables categorical interpretation, classifying results in clinical, borderline and nonclinical symptoms. The reliability of CBCL for children aged 1.5 to 5 years was .85 , sensitivity was $84.2 \%$, and specificity was 74 . For children age 6 to 18 years, the CBCL had internal consistency of .78-.97 (Achenbach \& Rescorla, 2010).

To assess children's quality of life, parents completed the Health Utilities Index (HUI 3, Horsman et al., 2003). This questionnaire is composed of eight attributes: vision, hearing, speaking, ambulation, quickness, emotional state, cognition and pain. Each attribute presents five or six different levels ranging from simple function to most abnormal function. It presents a descriptive system of health status and a mathematic algorithm to assign a value to each attribute. The score obtained ranges from 0 to 1 , in which 1 means perfect health. The reliability of translation to Brazilian Portuguese was attested by level of concordance between different types of respondents (patient, physician, and nurse) in both specific attributes and general score. There was evidence of convergent validity of results of a Brazilian sample compared with samples from other South American countries and Canada (Shimoda et al., 2005).

We used medical records to collect sociodemographic data (the child's date of birth, sex, and level of formal education of the child and the mother's age, marital status, education level and occupation) and clinical data (gestational age, weight at birth, adequacy of weight at birth, 5-minutes Apgar score, hospital readmissions in the first year of life, diagnosis about development made at the last medical consultation).

\section{Procedure}

Data collection. After signing the consent term, parents completed the quality-of-life scale, followed by the behavioral assessment. Next, the cognitive test was administered to the children, and at the end data from medical records were collected.

Data analysis. Instruments were corrected according to respective norms. Descriptive statistical data were obtained; after that we calculated absolute and relative frequencies of discrete variables and median, and amplitude of variation of continuous variables. Next, we looked for an association between quality of life and clinical data, sociodemographic data, cognitive assessment and behavioral problems. Spearman's correlation coefficient was used for analysis of continuous variables and Mann-Whitney nonparametric tests to evaluate the association of discrete and continuous variables. To verify possible predictor variables of quality of life, including weight and gestational age of the variables that showed statistically significant relationship in isolated analysis, and subtracting the confounding variables, an analysis of multiple logistic regression was done. A $5 \%$ significance level was used for results.

\section{Ethical Considerations}

This project was approved by the Ethical Research Committee of Medical School in Botucatu at Universidade Estadual Paulista (Protocol n. 3241-2009).

\section{Results}

In relation to cognitive development, $56.1 \%$ of children had good cognitive performance (i.e., median or higher intellectual level); $22.8 \%$, borderline; $8.8 \%$, intellectual impairment; and $12.3 \%$, unable to perform evaluation because of impairments and important emotional difficulties (autism, excessive shyness). Means of total IQ, EIQ, and VIQ remained close at 85.5 (50-113), 86 (56-120), and 85 (53122), respectively.

There was an increase in total behavior problems in children older than 6 years (44\%), assessed with the CBCL instrument from 6 to 18 years compared with 5 years $(8.3 \%)$, assessed by CBCL from 1.5 to 5 years. In this study we combined borderline cases with nonclinical cases. In children age 5 years, there was a slight predominance of internalizing problems $(33.3 \%)$ in relation to externalizing $(25 \%)$, but in children aged 6 years or older the relationship was inverted, with higher prevalence of externalizing problems (33.3\%) in relation to internalizing $(26.7 \%)$ and predominance of aggressive behavior (17.8\%). Considering behavior problems that were not part of the externalizing and internalizing axis, we verified more prevalence of attention problems (17.8\%) in schooling phase.

Mean quality-of-life score was .93 , indicating mild impairment in quality of life of children; observing minimal values, we found that attributes with higher impairments were ambulation, cognition, vision and hearing (Table 1).

Table 1

Median, Minimal and Maximal Values of Quality of Life Indexes Assessment of Quality of Life of HUI

\begin{tabular}{lcc}
\multicolumn{1}{c}{ Attributes } & Mdn & Min-Max \\
\hline HUI vision & 1.0 & $0.61-1.0$ \\
HUI hearing & 1.0 & $0.61-1.0$ \\
HUI speaking & 1.0 & $0.68-1.0$ \\
HUI quickness & 1.0 & $0.95-1.0$ \\
HUI ambulation & 1.0 & $0.58-1.0$ \\
HUI cognition & 1.0 & $0.60-1.0$ \\
HUI emotion & 1.0 & $0.95-1.0$ \\
HUI pain & 1.0 & $0.90-1.0$ \\
HUI total & 0.93 & $-0.09-1.0$
\end{tabular}

Note. HUI: Health Utilities Inc.

According to results of Table 2, there was a significant association of quality of life with maternal occupation $(p=$ $.02)$, sex $(p=.01)$, hospital readmission in the first day of life $(p=.01)$ and classification of NPMD $(p=.03)$. There was also an association with total IQ, EIQ and VIQ $(p=.01, .02$, and .03 , respectively), as well as total behavioral problems, internalizing and externalizing problems $(p=.01, .02$, and .01$)$. 
Table 2

Associations and Significant Correlations $(p \leq .05)$ of Quality of Life With Sociodemographic and Clinical Data and Cognitive and Behavioral and Cognitive Assessment

\begin{tabular}{|c|c|c|}
\hline \multirow{2}{*}{ Sociodemographic and Clinical Variables ${ }^{\mathrm{a}}$} & \multicolumn{2}{|c|}{ HUI } \\
\hline & Mdn (Min-Max) & $p$ value \\
\hline \multicolumn{3}{|l|}{ Maternal occupation } \\
\hline No work & $1.00(0.85-1.00)$ & \multirow{2}{*}{.02} \\
\hline Work & $0.88(0.20-1.00)$ & \\
\hline \multicolumn{3}{|l|}{ Sex of the child } \\
\hline Male & $0.93(0.20-1.00)$ & \multirow{2}{*}{.01} \\
\hline Female & $1.00(0.94-1.00)$ & \\
\hline \multicolumn{3}{|l|}{ Hospital readmission in 1st year of life } \\
\hline Yes & $0.88(0.35-0.94)$ & \multirow{2}{*}{.01} \\
\hline No & $1.00(0.20-1.00)$ & \\
\hline \multicolumn{3}{|c|}{ Checking development during medical consultation } \\
\hline $\mathrm{NPMD}^{\mathrm{b}}$ & $0.94(0.20-1.00)$ & \multirow{2}{*}{.03} \\
\hline $\mathrm{GNPM}^{\mathrm{c}}$ & $1.00(0.85-1.00)$ & \\
\hline \multicolumn{3}{|l|}{ Cognitive Assessment Indexes ${ }^{\mathrm{d}}$} \\
\hline Total IQ & & .01 \\
\hline Execution IQ & & .02 \\
\hline Verbal IQ & & .03 \\
\hline \multicolumn{3}{|l|}{ Behavioral Assessment Indexes ${ }^{d}$} \\
\hline Total problems & & .01 \\
\hline Internalizing problems & & .02 \\
\hline Externalizing problems & & .01 \\
\hline
\end{tabular}

Note. ${ }^{a}$ Use of non-parametric Mann-Whitney test, ${ }^{\mathrm{b}} \mathrm{NPMD}=$ neuropsychomotor development delay, ${ }^{\mathrm{c}} \mathrm{GNPM}=\mathrm{Good}$ neuropsychomotor development, ${ }^{\mathrm{d}}$ Use of correlation of Spearman's positions.

In a multiple logistic regression model, predictors of risk for impaired quality of life were participant's sex $(p=.04)$ and presence of total behavioral problems $(p=.05)$. Boys had a roughly $6 \%$ greater chance of poor quality of life than girls, and children with total behavioral problems had a $16 \%$ greater chance of poor quality of life in relation to children without behavioral problems (Table 3 ).

Table 3

Multiple Logistic Regression for Impairment in Quality of Life of Prematurely Born Children at School Age

\begin{tabular}{|c|c|c|c|c|}
\hline Variables & Coef. (EP) & $p$ value & OR & $95 \% \mathrm{CI}$ \\
\hline Sex & $1.877(0.903)$ & .038 & 6.535 & {$[1.114,38.345]$} \\
\hline Gestational age & $0.133(0.1)$ & .451 & 1.142 & {$[0.809,1.612]$} \\
\hline Hospital readmission & $0.284(0.803)$ & .724 & 1.329 & {$[0.275,6.415]$} \\
\hline Total IQ & $1.422(0.775)$ & .067 & 4.144 & {$[0.907,18.936]$} \\
\hline Internalizing problems & $0.430(1.020)$ & .673 & 1.537 & {$[0.208,11.347]$} \\
\hline Externalizing problems & $-1.802(0.191)$ & .191 & 0.165 & {$[0.011,2.457]$} \\
\hline Total behavioral problems & $2.801(2.423)$ & .050 & 16.456 & {$[1.012,267.757]$} \\
\hline
\end{tabular}

Note. $p$ values lower than $5 \%$ in bold.

In cognitive assessment, most children had medium or high achievement (56.1\%) and median total IQ, VIQ and EIQ were higher than 85.0. Other studies also found that premature children evaluated at different ages did not have significant cognitive deficits, although median performance was lower than in the control group (Maggi, Magalhães, Campos, \& Bouzada, 2014). However, Neubauer, Voss, and
Kattner (2008) and Stahlmann et al. (2009), in cohort studies, observed a percentage of premature children with normal intelligence lower than that in our study. This result may be due to the fact that they included patients with cerebral palsy and autism who, although they were not evaluated by standardized tests, were classified as special needs individuals. 
Saigal, Pinelli, Hoult, Kim, and Boyle (2003) evaluated extremely premature children from different countries aged between 8 and 11 years and found percentages of children with delays ranging from $44 \%$ to $62 \%$; these large variations depended on the country and possibly were due to the site where collection took place (residence or hospital), the method used, greater or lower intensity of neonatal care. Therefore, the variation in rates could reflect the economic and social differences among the countries.

Best cognitive performance of children of our sample can be attributed to neonate risk indexes more favorable than those found in other studies with extremely premature children (Castro, Rugolo, \& Margotto, 2012; Leversen et al., 2011), such as low prevalence of extremely low birth weight children and SGA, children with good recovery for clinical risk at 5 minutes after birth and consequent time of reduced hospitalization (median, 52 days). In addition, $51.1 \%$ of mothers had completed elementary school; they had 8 or more years of formal education. Evidence in the literature shows that mothers with higher formal education often better stimulate their children with different approaches, therefore actuating more actively for cognitive development of children, both full-term or preterm children (Fraga, Linhares, Carvalho, \& Martinez, 2008).

In relation to behavioral problems, $8.5 \%$ of children aged 5 years and $44.4 \%$ of children older than 6 years who were enrolled in elementary school had behavioral problems, with a higher percentage than those having externalizing problems, including aggressive behavior. These indexes reflect prevalence greater than or close to those found in other studies (Espírito Santo, Portuguez, \& Nunes, 2009; Ketharanathan, Lee, \& Mol, 2011; Oliveira, Enumo, Queiroz, \& Azevedo Junior, 2011; Samara, Marlow, \& Wolke, 2008; Silveira \& Enumo, 2012; Stahlmann et al., 2009).

Although diversity of results, possibly associated with use of different instrument of assessment and differences in composition of the sample, the similar standards of behavioral problems of children born with extremely low weight $(<$ $1,000 \mathrm{~g}$ ), especially difficulties with social interaction, thinking and attention give strength to explanations based on biologic mechanisms. According to Samara et al. (2008), behavioral problems of extremely low-gestational-age children would be associated with presence of neurologic and cognitive problems, as well as size, complexity and cerebral development. Premature birth would cause functional changes and cerebral structural, which can lead to problems, including behavioral problems related to disorders of the amygdala or prefrontal cortex (Quesada et al., 2014).

However, for social problems, it is also necessary to consider the role of parental behavior, as well as the tendency toward overprotection of children perceived as weak for those who permit use of social-emotional behavior inadequate for adaptation. In a recent review, Moreira, Magalhães, and Alves (2014) observed that most studies with prematurely born children identified the following as risk factors: behavior problems, socioeconomic level, maternal education, ethics, family conflicts and maternal distress.

The percentage of school-age children with behavioral problems was higher than in preschool children. In the literature, results of individuals of preschool age are still inconclusive. Researchers who used the CBCL (Ketharanathan et al., 2011; Oliveira et al., 2011; Silveira \& Enumo, 2012) obtained results similar to those in the present study. Espírito Santo et al. (2009) used other instruments and verified that $60 \%$ of preschoolers had behavioral problems. There is a need to consider that, in addition to children being evaluated with different instruments, participants of the study of Espírito Santo et al. (2009) were predominantly extremely premature, with a gestational age less than 26 weeks, and it was already proved that the lower the gestational age and weight at birth, the higher the risk for emotional and behavioral changes during development (Moreira et al., 2014).

Difference in frequency of behavioral problems in two age ranges can also be related to a more accurate paternal perception of older children. During the schooling phase, parents became worried about possible deficits of their child; there is more knowledge about expectations of development for this age range, and parents will compare the development of their children with that of their peers with a more attentive eye (Arruda \& Marcon, 2010).

In our study of quality of life, we verified mild impairment. Scores were lower in children with difficulties with ambulation, vision, and hearing and those with cognitive impairment. When we sought to determine the association of quality of life of prematurely born children with different sociodemographic conditions, we verified that mothers who worked outside the home evaluated their children as having worse quality of life than mothers who did not work. This topic - the role of maternal occupation in development and quality of life of a child, especially within the first cycles of life - is controversial in the literature. Sometimes it appears to be a risk factor and other times a protective factor. On the one hand, mothers who work might be less available to promote activities for development and feel guiltier to be away from their child. On the other hand, the income obtained with the mother's work can facilitate access to toys and other resources, therefore indirectly enabling higher stimulation of the child. Still, a mother's satisfaction with her occupation would promote her self-esteem, motivating positive experiences in relationship with her children (Fraga et al., 2008; Ribeiro, Perosa, \& Padovani, 2014).

In relation to child-specific variables, although weight at birth and gestational age did not show a significant association with quality of life, indicators of higher commitment and sequelae from premature birth (hospital readmission in the first year of life, NPMD found in medical consultation, and behavioral problems) were associated with poor quality of life. More than half of the sample had respiratory discomfort and asphyxia at birth, features that make the respiratory system more susceptible to new infection; these factors are associated with longer hospital stay and increased hospital readmissions after discharge (Castro et al., 2012), posing difficulty for adaption and development and, consequently, leading to worse quality of life.

Significant association between classification of physician and evaluation of quality of life may be due to children with scores lower than those of children with visible 
sequelae, such as ambulation, hearing, and visual impairment and cerebral palsy, easily diagnosed by the professional. Around half of participants of the study (49\%) were classified with NPMD by the physician. This is a higher percentage with NPMD than in other studies developed in the Brazilian content (Silveira \& Enumo, 2012; Ribeiro et al., 2014), but comparison of results should be done cautiously because the studies involved children of differing ages and type of risk and used diverse methods for assessment. The studies mentioned used standardized instruments (in general, the Denver II or Bayley scale); in the current study, physicians diagnosed NPMD by observing the child and according to reports of the mother. In our study, when cognitive development of the child was evaluated with a standardized test, indexes for delay decreased.

In relation to cognitive performance and behavioral problem, in agreement with the literature (Dahl et al., 2006; Samara et al., 2008; Verdehus et al., 2015), we observed a significant relationship between these variables and quality of life. Behavioral problems, however, were maintained as risk factor for quality of life in the final regression.

Another risk factor for quality of life was sex; boys had a $6.5 \%$ greater chance of impairment than girls. In the literature, few studies on quality of life of premature compare results by sex, but studies on other aspects of development, such as cognition or behavioral problems, have also observed that boys had worse development than girls (Méio, Lopes, \& Morsch, 2003; Samara et al., 2008). According to Johnston e Hagberg (2007), reasons that behavior disorders are more common in male individuals are not clearly defined, but evidence suggests that prematurely born males have cerebral white matter, which is more vulnerable to injuries and ventricular hemorrhages. According to Dahl et al. (2006), in addition to biologic aspects, parents seem to present more difficulty detecting behavior problem in girls, which compromises the comparison with boys.

Some limitations of this study must be considered. First, the sample size was small. National studies, especially longitudinal studies, have had difficulty finding individuals to participate because of lack of update in records, the population's difficulty with mobility, difficulty accessing collecting centers, and lack of interest of the population in participating, which lead to high costs of research (Macarini, Martins, Minetto, \& Vieira, 2010). Although we chose a service with good references with follow-up of participants until school age, with several contact attempts and offers for a personal assessment (including guidance for professors or referral to specialized services), only about $30 \%$ of the 197 children who met inclusion criteria participated in the study. For any future studies, we suggest that financial support be obtained and that investigators collaborate with other research groups in order to gather more representative samples.

We also used two nonstandardized instruments for the Brazilian population: the CBCL and HUI 3. However, there are instruments that already have a Brazilian version and had been used in other national investigations. Another limitation to be considered is the parental completion of quality-oflife questionnaires. In recent years, researchers have been concerned about the degree of concordance in perception of parents and children for a variety of aspects, including satisfaction with the child's quality of life, attesting that this is a highly subjective assessment that can be done only by the individual him/herself. However, most instruments for quality of life for children at the age range used in our study were answered by adults. Some studies have shown that young children have some understanding about health/ disease process; therefore, they suggest investing in the creation of instrument to evaluate the child him/herself.

Because of the scarcity of information in the literature, our study aimed to contribute to the characterization of cognitive and behavioral performance and quality of life of preschool and school-age children who had been born prematurely at extremely low weight, as well as to identify some risk factors. According to our results, most children had good quality of life and had lower scores those who had physical, sensorial and cognitive difficulties, which indicates that premature children without sequelae, may have benefitted by better birth conditions, investments at birth and during the first years of life, which may have improved their quality of life when they reach school age.

Despite the limitations observed, our study data enabled analysis of multiple logistic regression and identification of risk factors for quality of life of these children. In agreement with the literature, predictor variables of risk were multidetermined and associated with both biological and environmental factors. Behavioral problems appear as the main risk factor for good quality of life in premature children, especially those of school age. These results point out the need to implement preventive health measures to reduce prematurity rates, as well as create services for systematic follow-up to immediately identify difficulties faced by children and propose guidance for parents and professors, as well as international plans that may benefit the children before they enter school and may facilitate their adaptation.

\section{References}

Achenbach, T. M., \& Rescorla, L. A. (2010). Mental health practitioners' guide for the Achenbach System of Empirically Based Assessment (ASEBA, 7th ed.). Burlington, VT: Research Center for Children, Youth \& Families.

Arruda, D. C., \& Marcon, S. S. (2010). Experiência da família ao conviver com sequelas decorrentes da prematuridade do filho [Family experience of dealing with sequels of the prematurity of a child]. Revista Brasileira de Enfermagem, 63(4), 595-602. doi:10.1590/S0034-71672010000400015

Castro, M. P., Rugolo, L. M. S. S., \& Margotto, P. R. (2012). Sobrevida e morbidade em prematuros com menos de 32 semanas de gestação na região central do Brasil [Survival and morbidity of premature babies with less than 32 weeks of gestation in the central region of Brazil]. Revista Brasileira de Ginecologia e Obstetrícia, 34(5), 235-242. doi:10.1590/S0100-72032012000500008 
Dahl, L. B., Kaaresen, P. I., Tunby, J., Handegard, B. H., Kvernmo, S., \& Ronning, J. A. (2006). Emotional, behavioral, social and academic outcomes in adolescents born with very low birth weight. Pediatrics, 118(2), e449459. doi:10.1542/peds.2005-3024

Espírito Santo, J. L., Portuguez, M. W., \& Nunes, M. L. (2009). Cognitive and behavioral status of low birth weight preterm children raised in a developing country at preschool age. Jornal de Pediatria, 85(1), 35-41. doi:10.1590/S0021-75572009000100007

Fraga, D. A., Linhares, M. B. M., Carvalho, A. E. V., \& Martinez, F. E. (2008). Desenvolvimento de bebês nascidos pré-termo e indicadores emocionais maternos [Development of preterm infants and mothers' emotional indicators]. Psicologia: Reflexão e Crítica, 21(1), 33-41. doi:10.1590/S0102-79722008000100005

Hallin, A. L., \& Stjernqvist, K. (2011). Adolescents born extremely preterm: Behavioral outcomes and quality of life. Scandinavian Journal of Psychology, 52(3), 251256. doi:10.1111/j.1467-9450.2010.00850.x

Horsman, J., Furlong, W., Feeny, D., \& Torrance, G. (2003). The Health Utilities Index (HUI): Concepts, measurement properties and applications. Health and Quality of Life Outcomes, 1, 54. doi:10.1186/1477-7525-1-54

Johnston, M. V., \& Hagberg, H. (2007). Sex and the pathogenesis of cerebral palsy. Development Medicine \& Child Neurology, 49(1), 74-78. doi:10.1017/ S0012162207000199.x

Ketharanathan, N., Lee, W., \& Mol, A. C. (2011). Healthrelated quality of life, emotional and behavioral problems in mild to moderate prematures at (pre-) school age. Early Human Development, 87(10), 705-709. doi:10.1016/j. earlhumdev.2011.05.011

Leversen, K. T., Sommerfelt, K., Rønnestad, A., Kaaresen, P. I., Farstad, T., Skranes, J., . . Markestad, T. (2011). Prediction of neurodevelopmental and sensory outcome at 5 years in Norwegian children born extremely preterm. Pediatrics, 127(3), e630-638. doi:10.1542/peds.2010-1001

Macarini, S. M., Martins, G. D. F., Minetto, M. F. J., \& Vieira, M. L. (2010). Práticas parentais: Uma revisão da literatura brasileira [Parental practices: A review of Brazilian literature]. Arquivos Brasileiros de Psicologia, 62(1), 119-134.

Maggi, E. F., Magalhães, L. C., Campos, A. F., \& Bouzada, M. C. F. (2014). Preterm children have unfavorable motor, cognitive, and functional performance when compared to term children of preschool age. Jornal de Pediatria, 90(4), 377-383. doi:10.1016/j.jped.2013.10.005

March of Dimes, Partnership for Maternal, Newborn \& Child Health, Save the Children, World Health Organization. (2012). Born too soon: The global action report on preterm birth. Geneva: World Health Organization. Retrieved from http://whqlibdoc.who.int/ publications/2012/9789241503433_eng.pdf

Matijasevich, A., Silveira, M. F., Matos, A. C. G., Rabello Neto, D., Fernandes, R. M., Maranhão, A. G., . . Victora,
C. G. (2013). Estimativas corrigidas da prevalência de nascimentos pré-termo no Brasil, 2000 a 2011 [Improved estimates of preterm birth prevalence in Brazil, 20002011]. Epidemiologia e Serviços de Saúde, 22(4), 557564. doi:10.5123/S1679-49742013000400002

Méio, M. D. B. B., Lopes, C. S., \& Morsch, D. S. (2003). Fatores prognósticos para o desenvolvimento cognitivo de prematuros de muito baixo peso [Prognostic factors for cognitive development of very low birth weight premature children]. Revista de Saúde Pública, 37(3), 311-318. doi:10.1590/S0034-89102003000300008

Moreira, R. S., Magalhães, L. C., \& Alves, C. R. L. (2014). Effect of preterm birth on motor development, behavior, and school performance of school-age children: A systematic review. Jornal de Pediatria, 90(2), 119-134. doi:10.1016/j.jped.2013.05.010

Neubauer, A. P., Voss, W., \& Kattner, E. (2008). Outcome of extremely low birth weight survivors at school age: The influence of perinatal parameters on neurodevelopment. European Journal of Pediatrics, 167(1), 87-95. doi:10.1007/s00431-007-0435-x

Oliveira, C. G. T., Enumo, S. R. F., Queiroz, S. S., \& Azevedo Junior, R. R. (2011). Indicadores cognitivos, linguísticos, comportamentais e acadêmicos de pré-escolares nascidos pré-termo e a termo [Cognitive, linguistic, behavioral and academic indicators of preterm and full term born preschool children]. Psicologia: Teoria e Pesquisa, 27(3), 283-290. doi:10.1590/S0102-37722011000300003

Quesada, A. A., Tristão, R. M., Pratesi, R., \& Wolf, O. T. (2014). Hyper-responsiveness to acute stress, emotional problems and poorer memory in former preterm children. Stress, 17(5), 389-399. doi:10.3109/10253890.2014.949667

Ribeiro, D. G., Perosa, G. B., \& Padovani, F. H. P. (2014). Fatores de risco para o desenvolvimento de crianças atendidas em Unidades de Saúde da Família, ao final do primeiro ano de vida: Aspectos sociodemográficos e de saúde mental materna [Risk factors for impaired development in children attended at family health units at the end of the first year of life: Socio-demographic aspects and maternal mental health]. Ciência \& Saúde Coletiva, 19(1), 215-226. doi:10.1590/1413-81232014191.1904

Saigal, S., Feeny, D., Furlong, W., Rosenbaum, P., Burrows, E., \& Torrance, G. (1994). Comparison of the health related quality of life of extremely low birth weight children and a reference group of children at age eight years. Journal of Pediatrics, 125(3), 418-425. doi:10.1016/S00223476(05)83289-5

Saigal, S., Pinelli, J., Hoult, L., Kim, M. M., \& Boyle, M. (2003). Psychopathology and social competencies of adolescents who were extremely low birth weight. Pediatrics, 111(5 Pt 1), 969-975.

Samara, M., Marlow, N., \& Wolke, D. (2008). Pervasive behavior problems at 6 years of age in a total-population sample of children born at $</=25$ weeks of gestation. Pediatrics, 122(3), 562-573. doi:10.1542/peds.2007-3231

Silveira, K. A., \& Enumo, S. R. F. (2012). Biopsychosocial risks to development in preterm and low birth weight. Paidéia (Ribeirão Preto), 22(53), 335-345. 
doi:10.1590/1982-43272253201305

Shimoda, S., Camargo, B. S., Horsman, J., Furlong, W., Lopes, L. F., Seber, A., \& Barr, R. D. (2005). Translation and cultural adaptation of Health Utilities Index (HUI) Mark 2 (HUI2) and Mark 3 (HUI3) with application to survivors of childhood cancer in Brazil. Quality of Life Research, 14(5), 1407-1412. doi:10.1007/s11136-004-6127-3

Soares, A. H. R., Martins, A. J., Lopes, M. C. B., Britto, J. A. A., Oliveira, C. Q., \& Moreira, M. C. N. (2011). Qualidade de vida de crianças e adolescentes: Uma revisão bibliográfica [Quality of life of children and adolescents: A bibliographical review]. Ciência \& Saúde Coletiva, 16(7), 3197-3206. doi:10.1590/S141381232011000800019

Stahlmann, N., Rapp, M., Herting, E., \& Thyen, U. (2009). Outcome of extremely premature infants at early school age: Health-related quality of life and neurosensory, cognitive, and behavioral outcomes in a population-based in Northern Germany. Neuropediatrics, 40(3), 112-119. doi:10.1055/s-0029-1243166

The WHOQOL Group. (1995). The World Health Organization Quality of Life assessment (WHOQOL): Position paper from the World Health Organization. Social Science \& Medicine, 41(10), 1403-1409. doi:10.1016/0277-9536(95)00112-K

Verdehus, B. J., Eide, G. E., Natvig, G. K., Markestad, T., Graue, M., \& Halvorsen, T. (2015). Health-related quality of life and emotional and behavioral difficulties after extreme preterm birth: Developmental trajectories. PeerJ, 3, e738. doi:10.7717/peerj.738

Vieira, M. E. B., \& Linhares, M. B. M. (2011). Developmental outcomes and quality of life in children born preterm at preschool- and school-age. Jornal de Pediatria, 87(4), 281-291. doi:10.2223/JPED.2096

Wechsler, D. (2002). WISC-III: Escala de inteligência Wechsler para crianças: Manual [WISC III: Weschsler Intelligence Scale for children: Manual] (V. L. M. Figueiredo, Trans., 3rd ed.). São Paulo, SP: Casa do Psicólogo.

Wechsler, D. (2006). Teste de inteligência para preescolares WPPSI: Manual [WPPSI-Wechsler Preschool and Primary Scale of Intelligence] (D. Ares, Trans.). Buenos Aires, Argentina: Paidós. (Original work published 1967)

Juliana Aparecida Martini has a master's degree in Collective Health from Universidade Estadual Paulista "Júlio de Mesquita Filho".

Flávia Helena Pereira Padovani is an Assistant Professor of the Medical School in Botucatu at Universidade Estadual Paulista "Júlio de Mesquita Filho".

Gimol Benzaquen Perosa is an Assistant Professor of the Medical School in Botucatu at Universidade Estadual Paulista "Júlio de Mesquita Filho".

Received: June 9, 2015

1st Revision: Nov. 19, 2015

Approved: Dec. 14, 2015
How to cite this article:

Martini, J. A., Padovani, F. H. P., \& Perosa, G. B. (2016). Quality of life of preterm children: Risk and protection factors. Paidéia (Ribeirão Preto), 26(65), 325-332. doi:10.1590/1982-43272665201610 